\title{
ASO Author Reflections: The Frailty of Patient Selection
}

\author{
Katherin Zambrano-Vera, MD ${ }^{1}$, Armando Sardi, MD, FACS ${ }^{1}{ }^{(\mathbb{D}}$, Michelle Sittig, $\mathbf{R N}^{1}$, and \\ Teresa Diaz-Montes, MD, MPh, FACOG ${ }^{2}$ \\ ${ }^{1}$ Department of Surgical Oncology, The Institute for Cancer Care, Mercy Medical Center, Baltimore, MD; ${ }^{2}$ Department of \\ Gynecologic Oncology, Ovarian Cancer Institute, Mercy Medical Center, Baltimore, MD
}

\section{PAST}

Ovarian cancer remains a leading cause of death for women in the US and increased age has typically been associated with worse prognosis. Patients older than 65 years are more likely to undergo conservative treatments due to fear of increased morbidity and mortality. ${ }^{1}$ Although some studies have shown age to be a poor prognostic factor for ovarian cancer, ${ }^{2}$ it should not be considered as the most important. Variables such as feasibility of cytoreduction, frailty, and performance status may be of greater importance when selecting patients for cytoreductive surgery plus hyperthermic chemotherapy (CRS/HIPEC).

\section{PRESENT}

Our study evaluated the outcomes of women diagnosed with advanced epithelial ovarian cancers treated with CRS/ HIPEC as an upfront therapy, CRS/HIPEC in combination with neoadjuvant chemotherapy, or CRS/HIPEC as a salvage treatment, each stratified by age cohorts, i.e. $<65$ or $\geq 65$ years. $^{3}$ The elderly patient group ( $\geq 65$ years) had a complete cytoreduction rate of $86 \%$ and tolerated the procedure, as evidenced by similar complication and mortality rates as the younger cohort. Although progression-free survival was shorter in older patients (23.9 vs. 45.6 months), the median overall survival was 33.5 months, demonstrating that a notable survival rate can

(C) Society of Surgical Oncology 2021

First Received: 30 November 2020

Accepted: 1 December 2020;

Published Online: 4 January 2021

A. Sardi, MD, FACS

e-mail: asardi@mdmercy.com be achieved. Age was not a worse prognostic factor in univariate or multivariate analysis, indicating the importance of patient selection when considering CRS/HIPEC as management for advanced ovarian cancers.

\section{FUTURE}

Patient selection is the most important factor for older patients with advanced stages of ovarian cancer when considering CRS/HIPEC. Comorbidities, frailty, performance status, and completeness of cytoreduction should be clinically considered rather than chronological age alone. The assessment of these criteria in future randomized studies is important to help characterize the role of CRS/ HIPEC in the treatment of advanced epithelial ovarian cancers.

DISCLOSURE Katherin Zambrano-Vera, Armando Sardi, Michelle Sittig, and Teresa Diaz-Montes declare no conflicts of interest.

\section{REFERENCES}

1. Bouchardy C, Rapiti E, Blagojevic S, Vlastos AT, Vlastos G. Older female cancer patients: importance, causes, and consequences of undertreatment. J Clin Oncol. 2007;25(14):1858-69.

2. Jørgensen TL, Teiblum S, Paludan M, et al. Significance of age and comorbidity on treatment modality, treatment adherence, and prognosis in elderly ovarian cancer patients. Gynecol Oncol. 2012;127(2):367-74.

3. Zambrano-Vera K, Sardi A, Diaz-Montes, T, et al. Outcomes in elderly ovarian cancer patients treated with cytoreductive surgery plus hyperthermic intraperitoneal chemotherapy (CRS/HIPEC). Ann Surg Oncol. 2021. https://doi.org/10.1245/s10434-020-09415-4.

Publisher's Note Springer Nature remains neutral with regard to jurisdictional claims in published maps and institutional affiliations. 